\title{
Enhancing Social Capital among Employees: Psychological Approach
}

\author{
Subia $\operatorname{Khan}^{1} *$, Mustafa Nadeem Kirmani ${ }^{2}$
}

\section{ABSTRACT}

All organizations aim to maximise commercial benefits and increase their products in the market. Employees play a significant role in the growth of any organization. The skills, training, personality and motivation of the employees are critical for organizational growth. Traditionally, it was believed that monetary incentives are the most robust factor to change employees' motivation toward work and thereby production of the company. Recent research, however, has shown that besides monetary incentive, there are other psychosocial factors which play an equally significant role in the production of the organization.

Positive psychological factors like hope, self-efficacy, resilience, optimism and social relations play a significant role in maintaining and enhancing employees work motivation and production. These are often known as capitals of the organizations. The importance of interpersonal relations at workplace has been highlighted in most of the organizations. Human connections, relatedness and bond are significant in creating positive relationships at work place. Interpersonal network and trusting relationships among people inside and outside the organization is known as social capital. The social capital depends on gamut of factors related to interpersonal skills of the employees and ambience of the organization.

Increasing social capital not only increases the production of the organization but also create positive bond and happiness among the employees. The current paper will focus on various psychological interventions which can help people to develop and enhance their relationships and intimacy with other employees thereby increasing the production and their happiness.

Keywords: Social Capital, Social Relations, Psychological Interventions

\footnotetext{
${ }^{1}$ Visiting faculty, Department of Social Work, Jamia Millia Islamia, New Delhi, India

${ }^{2}$ Clinical Psychologist, trained at NIMHANS, Bangalore, India

*Responding Author

(C) 2016, S Khan, M Kirmani; licensee IJIP. This is an Open Access Research distributed under the terms of the Creative Commons Attribution License (http://creativecommons.org/licenses/by/2.0), which permits unrestricted use, distribution, and reproduction in any Medium, provided the original work is properly cited.
} 


\section{Enhancing Social Capital among Employees: Psychological Approach}

Positive organizational aspect is an emerging area of study that views standard organizational behavioral issues through positive psychology perspective. Positive psychology paradigm has shifted the focus of psychology from finding the human weaknesses and limitations to focusing on human strengths and assets. It was started by Seligman in 1998 in his historic address at the American Psychological Association. Positive psychology is the study of conditions and processes that contribute to the flourishing or optimum functioning of people, groups and institutions. It consists of three basic concepts (Seligman, 1998).

1. Pleasant life: People are able to achieve pleasant life when they are able to experience positive emotions about their past, present and future lives.

2. Engaged life: The engaged life is felt when one is deeply involved and absorbed in what one is doing in multiple life roles, including love, work and play.

3. Meaningful life: The meaningful life is defined as using one's strengths in the service of something larger than oneself.

The concept of social capital has emerged from the positive psychological constructs. Human capital is one of the important aspects of positive organizational scholarship. It simply refers to people's resources being used for the development of the organization. Social capital comes under the umbrella of human capital. Social capital refers to the networks and trusting relationships among people that is formed inside and outside the organization. Hanafin first gave the idea of social capital as "those tangible substances that count for most in the daily lives of people: namely good will, fellowship, sympathy, and social intercourse among the individuals and families who make up a social unit” (Hanifan, 1916, p. 132). Flap (1991) argues that social capital is the combination of network size, the strength of interpersonal relationship and the resources possessed by those in the network.

The idea of building social capital by way of reciprocity has recently been explored by Grant (2013) in his book Give and Take. Building social capital requires people to have sufficient skills to initiate, build, maintain and enrich relationship with other people at workplace. Social capital is a skill, hence can be built in people. There are people in organizations who have deficits in social skills so they are not the best resource for building capital in the organization. Such people in the organizations need to be trained in social skills by professionals. The following section describes the nature, process, steps and techniques of social skills training and other psychological strategies that directly or indirectly help in building social capital.

1. Social skills training: Social skills are the ability to express both positive and negative feelings in the interpersonal context without suffering consequent loss of reinforcement. Such skill is demonstrated in a large variety of interpersonal contexts and involves the coordinated delivery of appropriate verbal and nonverbal responses. In addition, the socially skilled individual is attuned to the realities of the situation and is aware when he 


\section{Enhancing Social Capital among Employees: Psychological Approach}

is likely to be reinforced for his efforts. This social skills model addresses the relationship between social and problem solving skills on the one hand and social competence and social adjustment on the other. Social competence is defined as the ability to achieve desired goals. Social adjustment refers to an individual's actual attainment of those goals, including the ability to function in different social roles (e.g., worker, parent, spouse, student), to enjoy leisure and recreational activities, and to care for oneself. The social skills model postulates four assumptions about the relationships between social skills and problem solving skills and social functioning:

- Social competence requires the integration of a set of component behaviors

- Impairments in component skills contribute to poor social competence

- Social skills are learned or are learnable

- Deficits in social and problem solving skills can be rectified by skills training

\section{Components of social skills training}

Based on this broader conceptualization of social skills, social competence is conceptualized as requiring three different types of skills.

First, in order to be effective in a social situation, the person must be able to accurately perceive relevant situational parameters, such as their relationship to the other person, whether the setting is public or private, and the other person's affective response (i.e., social perception skills). Recognition of these situational features is crucial, as they may constrain the appropriateness of social behaviors. There is ample evidence showing that social perception skills, such as the inability to accurately perceive the facial expressions of others or recognize interpersonal problems, are correlated with poorer role performance in clinical populations.

Second, after the relevant social information has been extracted from a situation, the individual must be able to formulate a goal, generate possible response alternatives for achieving the goal, weigh the benefits and disadvantages of each possible solution, and choose the best solution. Although these cognitive skills may occur implicitly, they have an important bearing on the success of any plan, and hence are of direct relevance to an individual's social competence. In addition to the cognitive skills generally subsumed under the rubric of "problem solving skills," other cognitive skills can also influence social competence. Abstract thinking can be crucial for an individual to grasp a concept related to solving a particular problem or achieving a desired goal. Memory impairment may interfere with social competence by rendering it more difficult for individuals to learn from past mistakes or recall critical features of situations. Cognitive functioning has been found to be a robust predictor of psychosocial adjustment, with research suggesting that the ability to cognitively process socially-oriented information (i.e., social cognition) is especially critical to success in interpersonal spheres. 


\section{Enhancing Social Capital among Employees: Psychological Approach}

Third, after social perception and cognitive skills have been used to appraise a situation and formulate a plan of action, behavioral skills are required to carry out the plan. Behavioral skills refer to the actual behaviors emitted in interpersonal situations that are necessary to achieve a particular goal. Broadly speaking, behavioral skills can be divided into four different areas, including nonverbal components, paralinguistic skills, verbal content, and interactive balance. Nonverbal components are behaviors such as eye contact and use of gestures that convey meaning or affect during an interaction. Paralinguistic skills correspond to the vocal characteristics of speech, such as voice tone, loudness, and inflection. Like nonverbal components, paralinguistic skills often communicate vital information during an interaction, such as the speaker's mood or underlying motives.

\section{Components of social skills are given below}

Nonverbal behaviors, Eye contact, Facial expression, Posture Use of gestures, Body orientation ,Interpersonal distance, Paralinguistic skills, Loudness Tone, Pitch Affect Rate of speech, Clarity of speech, Duration of utterance, Verbal content, Verbal message, Choice of wording, Appropriateness of self-disclosure, Interactive balance, Smoothness of turn-taking, Use of social reinforcers (e.g., reflective listening skills) balance of time-talking. Social skills training can be used to train people having social skills deficits, people with depression, relationship difficulties and host of other conditions.

2. Problem solving: It is one of the most commonly applied cognitive-behavioral strategy to solve clinical and non-clinical problems. D'Zurilla \& Goldfried (1971) formulated a famous problem solving model. Problem solving approach can be used in conditions of academic difficulties, relationship difficulties, anger management, and host of psychiatric conditions like depression, anxiety disorders, schizophrenia, etc. It has been observed that people who face more difficulties and challenges in life often have poor problem skills. They are taught a series of steps to help them think through problems and solutions and to help them cope with problems in a more constructive way. Training in problem solving skills involves following a specific sequence of steps. These steps are designed to allow consideration of as many solutions as possible and to consider what is needed in order to put a chosen plan into action. Problem solving training aims to teach a process for approaching problems and achieving goals. In problem solving, the essential task is to educate clients how to think and approach psychological problems in a more systematic, rational, and empirically based manner. The basic steps of problem solving are given below:

a) Define the problem: Having defined the problem, the following three steps need to be followed.

- Get different opinions about the nature of the problem

- Define the problem or goal in behaviorally specific terms

- If the problem is shared by more than one person, make sure each one agrees on the definition 


\section{Enhancing Social Capital among Employees: Psychological Approach}

b) Generate possible solutions to the problem and find the advantage and disadvantages of each one

- Brainstorm as many different solutions as possible

- Do not evaluate any solutions at this time

- Be creative and include all ideas

c) Evaluate the solutions:

- Systematically evaluate one solution at a time

- Avoid settling on one "best" solution before reviewing all solutions

d) Select the best solution(s)

- Select the solution that seems most likely to be effective

- Consider how difficult the solution will be to implement

- Choose more than one solution if they can be easily combined

e) Plan on how to implement the solution(s)

- Consider what resources are needed to implement the solution (e.g., money, skills, information)

- Anticipate possible obstacles to implementing the solution

- Establish a time frame for implementing the solution(s)

- If more than one person is involved, establish specific tasks for each person

f) Review problem solving plan at a later time

- Plan a time to evaluate whether the problem solving plan was successful

- Do additional problem solving and modify the plan if the desired goal has not been obtained

- Praise all efforts at solving the problem, even if the problem is not entirely resolved

3. Focusing on people's strengths and appreciating them about those also help in building bond among people which in turn leads to build social capital.

4. Remember those people who have contributed significant things in your life and write letter of gratitude to them for what they have done for you. It may be anything healthy piece of advice, financial help, emotional support etc. It helps to build connections among people and thereby social capital.

5. Tell people about yourself. People won't trust others unless people are willing to trust them. It helps build connections.

6. Invite people to get involved. People want to become part of something bigger than themselves. They often have the desire to meet others and share common goals. So, it is important to invite them for every issue in the organization and seek their advice to find solution. Let us work together approach build cohesiveness and social connections.

7. Make people feel important in an organization and it is important to tell their contributions in the development of the organization. It will enhance their self-esteem 


\section{Enhancing Social Capital among Employees: Psychological Approach}

and self-efficacy. People with high self-efficacy and self-esteem make connections with others and relate with others in a healthy way. It helps to build social capital.

8. Accept people's mistakes. Human beings are infallible and can do mistakes. It is important to make people reflect about their mistakes, monitor their mistake related behaviour and provide chance for self correction. It creates health environment and connections with employees.

\section{CONCLUSIONS}

Organizations nowadays have started focusing on non monetary factors for employees' work place contentment and the development of the organization. Positive psychological factors like hope, optimism, self-efficacy and resilience have become the focus nowadays. Social capital has also emerged as an important factor for the organizational development and employees' happiness. There is a need that different organizations use the services of professional psychologists to train their staff in enhancing their interpersonal connections and thereby social capital. It will also contribute toward the growth and development of the institutes.

\section{Acknowledgments}

The author appreciates all those who participated in the study and helped to facilitate the research process.

\section{Conflict of Interests}

The author declared no conflict of interests.

\section{REFERENCES}

D'Zurilla, T. J., \& Goldfried, M. (1971). Problem-solving and behavior modificauon. Journal of Abnormal Psychology, 78, 104-126.

Flap, H, D. (1991) . Social Capital in the Reproduction of Inequality .Comparative Sociology of Family, Health and Education 20, 6179-7202 .

Grant, A. (2013). Give and take. New York, NY: Penguin Books.

Hanifan, L. J. (1916). The rural school community center. Annals of the American Academy of Policital and Social Science, 67, 130-138.

Luthans, F., Luthans, K. W., \& Luthans, B. C. (2004).Positive psychological capital: Beyond human and social capital. Business Horizons, 47(1), 45-50.

Seligman, M.E.P. (2002) Authentic Happiness: Using the New Positive Psychology to Realize Your Potential for Lasting Fulfillment. New York: Free Press.

How to cite this article: S Khan, M Kirmani (2016), Enhancing Social Capital among Employees: Psychological Approach, International Journal of Indian Psychology, Volume 3, Issue 4, No. 67, ISSN:2348-5396 (e), ISSN:2349-3429 (p), DIP:18.01.187/20160304, ISBN:9781-365-39397-6

(c) The International Journal of Indian Psychology, ISSN 2348-5396 (e)| ISSN: 2349-3429 (p) | 123 